\title{
Integration of information and communication technologies into the process of learning the course of English for specific purposes as one of the requirements for sustainable future development
}

\author{
Viktoriia Lemeshchenko-Lagoda ${ }^{1, *}$, Iryna $\operatorname{Kryvonos}^{1}$, and Oleksandr Kolodii ${ }^{2}$ \\ ${ }^{1}$ Dmytro Motornyi Tavria State Agrotechnological University, The Department of Foreign Languages, Melitopol, 72312, Ukraine \\ ${ }^{2}$ Dmytro Motornyi Tavria State Agrotechnological University, The Department of Technology of Structural Materials, Melitopol, 72312, \\ Ukraine
}

\begin{abstract}
One of the most effective ways to improve the process of teaching foreign languages for specific purposes is to use computer and Internet technologies in the education system. The computer-information model of education is a kind of transitional stage from the system of traditional methods of teaching foreign languages to the modern system of information education. The article describes the advantages and disadvantages of the most progressive and wide used technological means like computers, laptops, interactive whiteboards, tablet PCs and graphics tablets, whose implementation into the educational process can significantly increase the effectiveness of teaching foreign languages for specific purposes and help in organizing lessons. Moreover, various language learning multimedia tools such as Modular Object-Oriented Dynamic Learning Environment and digital presentations, and peculiarities of their use are highlighted. The research of experimental data has been carried out after several surveys among Tavria State Agrotechnological University students. The necessity of information technology implementation into the process of learning foreign language for specific purposes was analysed.
\end{abstract}

\section{Introduction}

According to the Sustainable Development Goals (SDGs) which have been adopted at the 70th session of the UN General Assembly, the providing high quality education is one of the most required conditions for sustainable future [1]. The rapid pace of changes in the world must integrate new perspectives in order to protect the environment, contribute to sustainable cities and community development, promote sustainable economic growth and create inclusive societies. The realization of these tasks requires a new approach to education.

The sustainable future development includes the cooperation and joint participation of professionals and experts from different backgrounds. Academic and labour migration has led to a growing need for learning foreign languages, not only for everyday communication but for successful communication with their colleagues from other countries. All these changes resulted in high demand for learning English as a language for specific purposes (ESP). Meanwhile, the 2030 Agenda for Sustainable Development emphasizes that learning opportunities should be increased and diversified, using a wide range of education and training modalities, so that all youth and adults can acquire relevant knowledge, skills and competencies for decent work and life [2]. Hence, critical thinking and problem solving, communication skills and teamwork, creativity and work-specific skills should be developed in the process of future specialists training. The course of English for specific purposes is aimed at acquisition of all mentioned above skills and forming the professional and communicative competence. In addition, the traditional teaching methods are expanded with the intensive introduction and application of new information technologies, as well as the use of all means of communication.

The purpose of this research is to analyse the influence of information and communication technologies (ICT) on the process of learning English for specific purposes which contributes to the formation of an intellectually developed creative person who is well oriented in the information space, ready for selfdevelopment and application of professional knowledge for sustainable future.

The development of revolutionary new products in the market of computer and office equipment is inevitably changing the relationship between the student and the teacher, and in general the entire education system. Today a vast majority of students often own computers (laptops, netbooks), tablets and readers with a high-speed Internet connection, which enable them to access any information in minutes. 
This has greatly influenced the teaching environment. Therefore, the teachers have to be not only the perfectly qualified specialists in their professional field but also to be competent in modern information and communication technologies. They should also be creative in producing and innovating new techniques and methods of teaching that could maximize the use of technology that fulfil students need in current time [3], understanding that the use of modern information technology is not a purpose itself, rather it is one of the most important components of the organization of the educational process in high school.

According to S. Symonenko et al., the practice of immersion into virtual environment in foreign language learning will enable students to feel themselves an integral part of the professionally oriented situation which is designed specifically to prepare the course participants for communication within. [4] Therefore, the common goal of all ESP teachers is to develop students' foreign-language communicative competence that would enable them to communicate at a professional level with specialists from other countries [5]. This implies a direct correlation between theoretical knowledge and practical skills in their specialty and foreign language learning. V. Klochko notes that students of higher education institutions - future specialists - need to acquire both professional competence and communicative foreign language competence. It is about acquiring the necessary knowledge, professional skills and abilities to use a foreign language in intercultural cooperation [6].

The specific nature of teaching a foreign language allows comprehensive use of information technology throughout the educational process, which significantly changes the model of learning, making the transition from teaching-centric to student-oriented system. The use of information and communication technologies contributes to the individualization of the main forms of learning and optimization of the acquisition of language structures at all levels, overcoming the monotony of the lesson in the process of forming foreign language communicative competence.

Authors of modern methods of teaching a foreign language consider information and communication technologies as means, methods and techniques of performing educational tasks and project work [7]; independent extracurricular work; creation of a virtual educational environment. Thus, the use of ICT makes it possible to control knowledge at all stages of learning the material, providing the necessary feedback between the teacher and the participants of the educational process, which helps to increase their level of knowledge and skills.

Taking into account the practical experience in teaching English for specific purposes, considerable attention should be paid to the use of multimedia technologies, which simultaneously use texts, graphics, video materials, sound effects, animation. All of this, together with interactive software, affects the emotional and conceptual areas, contribute to a more efficient assimilation of language material [7].

Teachers can use ready-made ICT tools (multimedia, educational software, digital presentations, etc.) during language training or create their own [8]. The advantage of the latter should be noted, because in this case the teacher has the opportunity to adapt the content of an ICT tool to the level of knowledge and skills of a particular group of students, to fill it with material that would be of interest to this group and would correspond to the curriculum and technical capabilities of a particular institution [9]. Therefore, the use of new information technologies greatly facilitates the activities of teachers and students in the process of learning the course of English for specific purposes.

\section{The use of computers and laptops for learning English for specific purposes}

S. Symonenko and V. Osadchyi put forward the idea that foreign language training of future specialists in any branch should keep pace with the realities of time and take into consideration existing transformations of communication in order to learn languages for the further successful functioning of specialists in their professional activities [10].

With the development of modern technology, computers and laptops have become learning tools that can visualize a variety of information. They affect all components of the training system: goals, content, methods and organizational forms of training, teaching aids, which makes it possible to solve complex pedagogical tasks, namely: the development of intellectual, creative potential, analytical thinking and self-realization. In addition, B. Drayton, J. Falk, K. Hobbs, J. Hammerman, and R. Stroud emphasized that the use of computer based classroom shows a real learning experience that increases learners' responsibility [11].

For the teacher, the amount of visual and video material in preparation for the lesson with this technical tool is unlimited, as there are many educational resources on any topic, and in various online libraries the specific visual materials can be found and reused.

According to AbdulMahmoud Ibrahim, ICTs help the student be exposed to language clockwise and definitely they help them to write and edit their work in order to produce a well published work. Likewise, computers encourage students to do extra work outside the classroom, play language games and, hopefully, gain extra exposure to the language and improve their progress in the language and support the studentcentered concept [12]. Therefore, computer-based training provides the opportunity to organize the independent work of each student.

Integrating computer means into a regular lesson allows the teacher to shift part of his work to a computer, while making the learning process more interesting and intensive. Moreover, the computer does not replace the teacher, but only complements him. The selection of training software depends primarily on the current training material, students' language skills and their abilities.

The noted capabilities of the computer make it an excellent technical tool for various kinds of explanations 
and generalizations of the phenomena of language, speech and speech activity.

Among the typical disadvantages of computerassisted instruction is abuse of computer effects and redundancy of colours. Moreover, it's very difficult to adapt ready-made educational computer software on a subject to a traditional lesson, since it does not always correspond to the curriculum, methodological goals, and didactic principles in teaching.

One of the most common ways of controlling the gained knowledge and language skills is accomplished with the help of open information systems, like the Moodle LMS. Moodle is a package for creating webbased courses and is quite favourable for learning ESP with a great opportunity for personalization that enables the teacher to create on-line courses with exceptionally rich interaction [13]. In other words, it is a learning management system, courses, a virtual learning environment that allows creating a holistic working space for all participants in the educational process.

The large-scale implementation of this system in the educational process of Dmytro Motornyi Tavria State Agrotechnological University (TSATU) began in 20142015. The Moodle system is focused on cooperation and interaction between the teacher and the student during the classroom and extracurricular activities for the joint implementation of educational tasks (Fig. 1). The teacher has the ability to transmit a huge amount of information and control the gained knowledge and organize the learning process more rationally, making easy and understandable tasks and topics for independent study remotely through this electronic system.

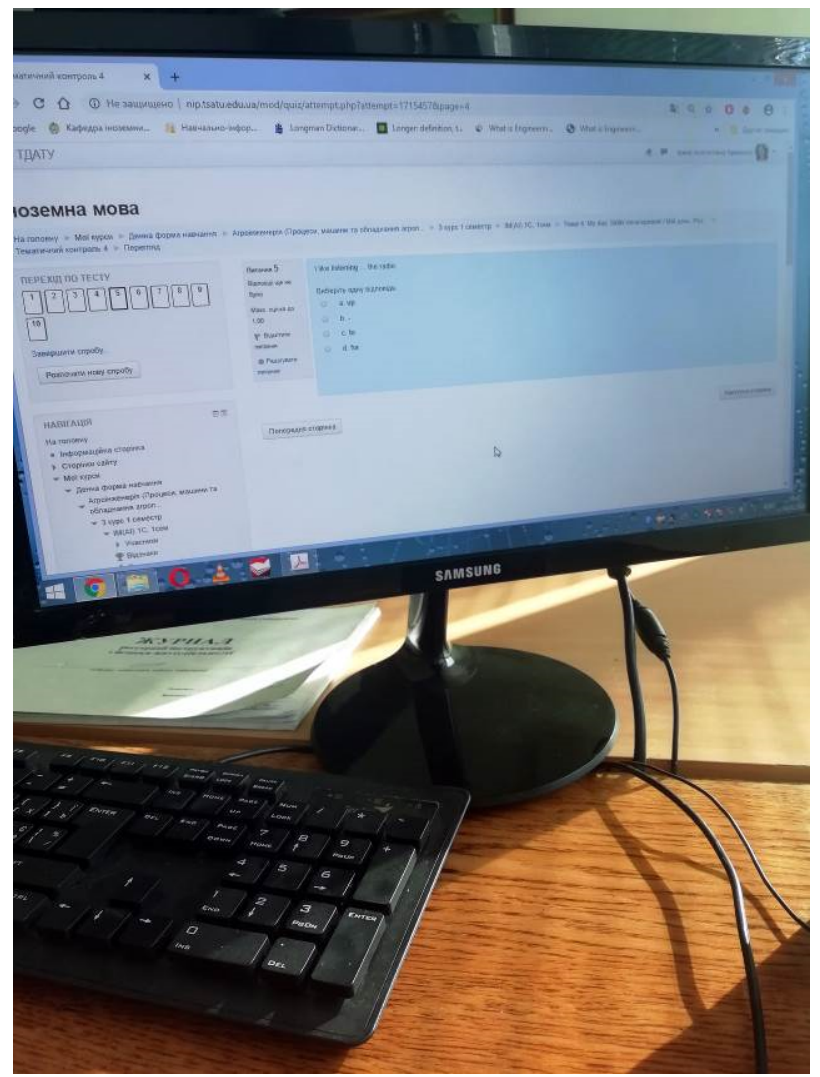

Fig. 1. ESP e-course based on Moodle LMS.
Teachers of the TSATU annually develop and actively use electronic educational and methodological complexes that include ESP curriculum, syllabus, selfstudy support packs and practical recommendations for studying foreign languages in a number of disciplines [14].

The named complexes are based on the use of modern e-learning technologies, which ensure the implementation of individual teaching areas with the direct supervision of a teacher and significantly increase the process efficiency of teaching a foreign language.

The advantage of using open information system is the mobility of training, since the electronic complex is available at any time in the classroom and outside the educational institution, so students can plan their curriculum, duration of the lesson and assignments at a time convenient for them, but taking into account the time limits established by developers.

Entering the Moodle LMS students choose a certain subject (Fig. 2). After reading and studying the material, strategies, recommendations, they consolidate their developed language skills by doing a test on each topic. At the end of the course, students must pass the final test in a fixed time and have a limited number of attempts. Their grades or score will be recorded in the group register. Furthermore, Marina D. Milovanović outlines the main advantage of Moodle system as the possibility to check the results right away [15].

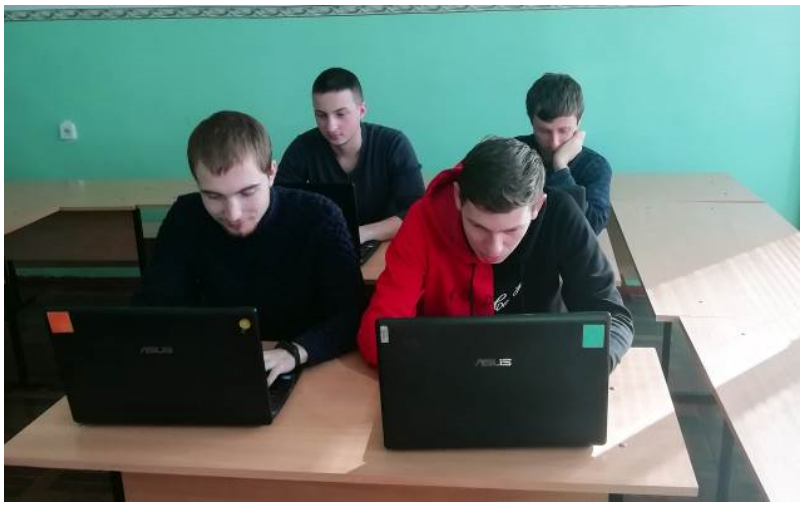

Fig. 2. Computer-assisted language learning in classroom.

Among the negative aspects of the Moodle system, in our opinion, is the fact that it is impossible to control the students' individual work in a distance. The teacher often has difficulties in defining the exact individual who completed the tasks and mastered the material to obtain a satisfactory grade, and be sure that no one else used the student's profile and helped him to get a higher grade.

In testing, it is impossible to exclude an element of randomness. For example, a student who does not answer a simple question may give the correct answer to a more complex one. The reason for this may be either a random mistake in the first question, or guessing the correct answer in the second. This situation can greatly affect the distortion of the test results and, accordingly, lead to the necessity of using the probability component in the analysis of the results.

As for the technical problems, one cannot but mention that the compilers of the mid tests and final tests 
establish a certain number of attempts to pass them and do not take into account the congestion of the system or problems with the Internet connection at home or in the audience of the educational institution. The system may shut down, the attempt will be lost and the score will not be recorded in the register.

The development of quality test control is a long and difficult process. To work correctly with the Moodle LMS, the teacher needs to undergo special training. To master the skills of filling the subjects of classes, a bank of test questions, enrolling groups of students and teachers in a particular course of a discipline. Similar training is necessary for students with explanations and a sample test, for example.

Tests of educational achievements used in the system to assess the quality of training, mainly help to measure the students' gained knowledge on particular language skills. On the other hand, the system restricts the possibility to evaluate such language activities as speaking and writing.

\section{Using interactive whiteboards for foreign language teaching}

An interactive whiteboard is one of the most modern teaching tools, the technology of work with which is being actively mastered today by teachers of various subjects. It is one of the most powerful visual presentation tools that give the opportunity to place a large number of diverse information, the density of which is much higher than on a regular board.

Fully functioning interactive boards are typically connected to a computer, a multimedia projector, a projector mounting kit, AV face plates and speakers. The image from the computer monitor is transmitted through the projector to an interactive whiteboard, and touches on its surface are sent back to the computer via a cable or through wireless communication interfaces and are processed by special software [16].

According to the main characteristics we distinguish interactive boards for direct or reverse projection. For direct projection, the projector is located directly in front of the surface of the interactive whiteboard, and in the opposite - behind it. Individual interactive whiteboard models can be equipped with special handheld personal computers for data exchange. There are also expensive models of interactive whiteboards that do not use the projector, but have got a large touch screen plasma panel.

There are three types of interactive whiteboards:

1. Boards that fix the surface resistance when they are touched.

Such boards have a soft and flexible surface consisting of two parts. The resistance fixing material is separated by a small gap from the rest surface of the board and transmits signals to the computer when a special membrane is triggered. Such boards can be controlled not only by special markers, but also by the usual touch of a board or pointer.

Special markers can also be configured (using the supplied software) to display different colours. Such boards are very suitable for educational institutions, as they are reliable and do not require any special gadgets that can be lost or broken [16].

2. Boards that fix electromagnetic pulses.

These boards, like traditional ones, have a solid surface. It is controlled by special battery-operated electromagnetic markers. The surface of the board is covered with a grid of thin wires that capture a small magnetic field emitted by the marker.

\section{Laser boards.}

Laser boards have a solid work surface with infrared laser scanners mounted on the surface. These scanners detect the movement of a special pen, colour coded and transmit them to a computer. Also close to this technology are the DViT (Digital Vision Touch) boards, which use small digital camcorders, located at the corners of the screen and capturing each touch [16].

The greatest effect can be obtained by a teacher using all the features of the board. The interactive whiteboard with the help of a special marker allows teachers to move drawings, photos and texts on its surface, copy them, rotate, resize and shape. With this marker, they can not only draw on the surface of the board, but also control computer software, push buttons, select and drag objects. The marker in this case replaces the computer mouse. This feature allows many computer software to be used with the interactive whiteboard, including most of the existing multimedia computer educational software.

Also, teachers working with an interactive whiteboard can increase the level of perception of the material by combining various forms of information transfer - visual, sound and tactile. During the lecture, they can use bright, multicolour schemes and graphics, animation accompanied by sound, interactive elements that respond to the actions of the teacher or student. If necessary, it is possible to enlarge one or another element drawn on the board surface with one hand movement. Thus, competent work with the interactive whiteboard helps to optimize the learning process.

Remotely, managing the presentation, the teacher has more opportunities to provide individual assistance to the students, because all the constructions, schemes that he had to complete on the board during the lecture, are already on the slides of the presentation. Therefore, presentations are the most accessible and effective educational means which can be used at various stages of the lesson and various types of lessons, depending on the goal set by the teacher. They provide an opportunity for the integrated development of the speech skills of a student in the process of learning foreign languages.

Holding presentations diversifies the educational process and allows involving students in cognitive activities. And the preparation of presentations by the students themselves is clearly practical, since in the future they will have to work in enterprises and organizations where presentations are an urgent need for successful work and the fulfilment of their functional duties.

For example, during English for specific purposes lessons the second-year students of specialty "Agronomy" are offered to present their own reports on 
the topic "Main peculiarities of modern education, its prospects and perspectives" using whiteboard technology. Thus, students have the opportunity to share their own thoughts on the set issue with others and manage the whole process of their presentation (Fig. 3).

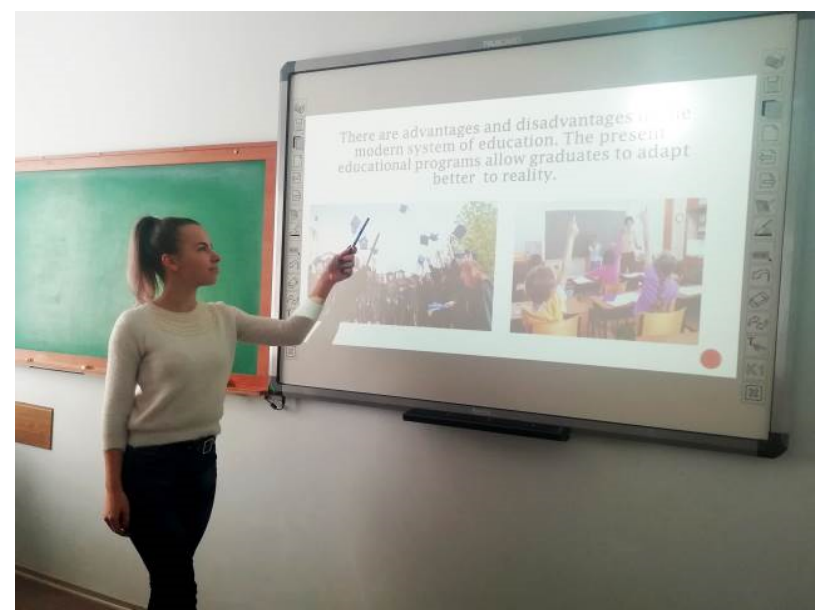

Fig. 3. Interactive whiteboard in foreign language class.

Interactive whiteboards enable them to show their slides, videos, schemes which can help students thoroughly explain their points of view. Moreover, whiteboards lower the psychological barrier, allowing students to overcome their fear of public speaking, technology and begin using modern technology in educational and professional spheres [17].

Like any other interactive tool working on whiteboards requires previous training and deep knowledge of appropriate software. Besides, the process of calibration should be done before the first using and after some periods of time. The amount of available functions depends on the model of whiteboard and thus the price can be too high.

\section{The role of tablet PC in learning English for specific purposes}

Recently, increasing attention has been given to the use of tablet PCs in the educational process, that combine handwriting, mobility and computing power to support student-centered learning.

It is worth noting that the universities and higher educational institutions of many developed countries are widely studying the benefits and innovative forms of using tablet PCs and stylus-based technologies [18]. In his work, J. Kromak explains that tablet computers contribute to the implementation of seven principles of educational practice:

- promote active interaction of participants in the educational process;

- encourage cooperation, that is, exchange of experience and working together;

- encourage an active attitude to learning;

- provide fast feedback;

- allocate time for the task;

- allow to communicate without restrictions;
- nurture a tolerant attitude to each participant in the educational process.

The above-mentioned principles are crucial for enhancing cognitive activity in the learning process, as compared to passive retrieval, which leads to the availability of high potential for tablets to improve the educational process due to significant changes and completely new aspects in the ways of interaction of all participants in the educational process. Despite its advantages, this technology is not yet fully recognized and widely used, especially in the field of foreign language teaching.

Tablet computers can be implemented into the process of learning a foreign language in order to improve and formulate the foreign language competence of future specialists of different fields. For this purpose, the work can be organized in pairs, groups and microgroups of permanent and variable stuff, and individually (Fig. 4).

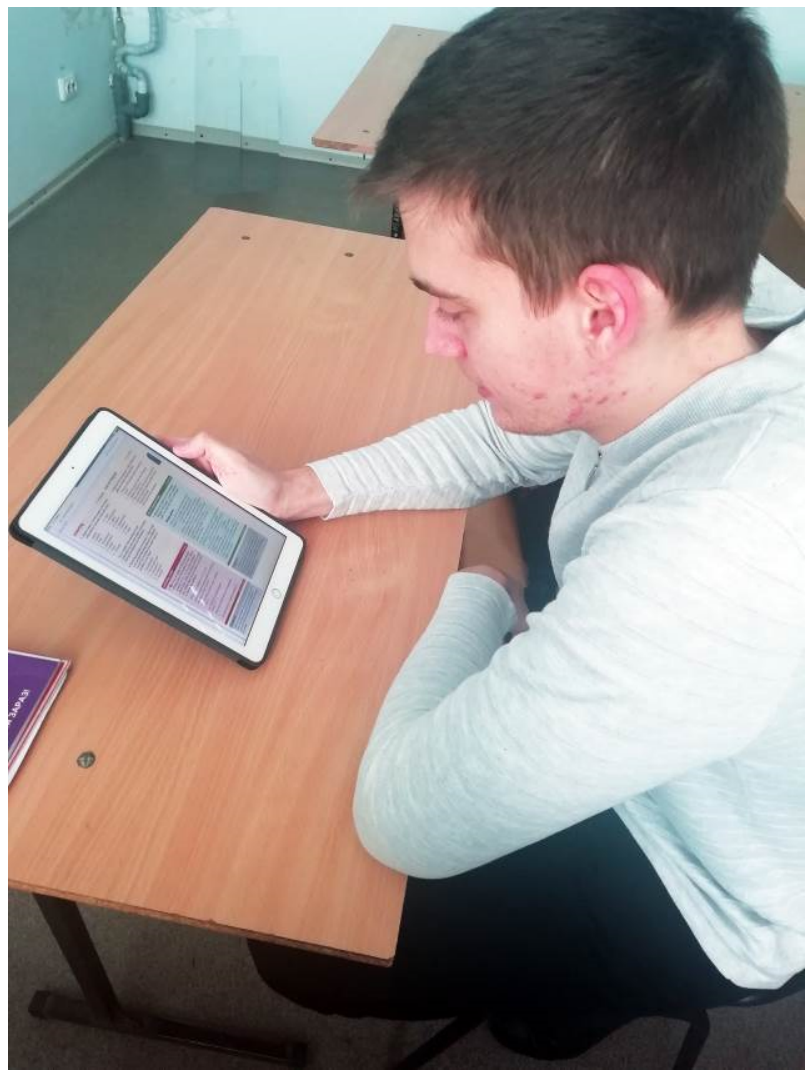

Fig. 4. Tablet PC use in the classroom.

For effective group work, students firstly receive plans describing the algorithm of group work, and then they organize the interaction and planning of activities by themselves. Tablet computers are used to provide the search of information while solving problems and act as the main tools for projects implementation.

To accomplish tasks set by the teacher, communication situations were developed in such a way aimed to provide a deep understanding not only of the new language material, but also the activation of professional knowledge that was previously acquired during the study of specialty disciplines. Such tasks are predominantly problem-oriented, and their 
implementation is realized through a combination of individual and group work. Thus, students are trained in oral and written communication in a foreign language in order to develop the ability to build logical and reasonable answers, to conduct polemics and discussion, processing information from scientific and popular science spheres.

Approximation of training to real production situations, modelling of specific production processes effectively contribute to the interest in the study of disciplines. That is why the development of communicative competence by means of ICT was carried out not only on the basis of the fulfilment of educational tasks, but also tasks of a professional nature both in the classroom and at the enterprises. In this regard, the aspect of ICT application has considerably expanded and the role of computer technologies in solving the educational and production tasks has been strengthened.

Thus, studying the topic "Soil preparing machines", the future specialists in the agro-engineering field were offered a situation directly related to their future professional activity:

"Imagine you are working in a team of agricultural engineers at one of the farm enterprises. The enterprise, expanding its production, has a rented field area. Your task is to determine what plough model will provide the best soil preparation for cereals (the ploughing depth is no more than $30 \mathrm{~cm}$, humidity is no more than $60 \%$ and slope of the field surface is no more than $10^{\circ}$. On the farm there are tractors of traction class 3 with an engine capacity of $150 \ldots 170 \mathrm{hp})$ ".

According to the task, students have to consider the main plough types that can be used under the given conditions, analysing their advantages and disadvantages, agree on one best model, and present their decision in the form of a mini-presentation to the audience with further discussion. In this case, the tablet acted not only as a tool for finding and selecting information, but also for creating the project presentation itself. They are also able to review material given by the teacher, use additional online materials, make the necessary calculations, and create their own slides. Taking into account that each student has its own tablet, all the tasks are shared among group mates so that each member of micro group tries to present the most appropriate plough model, trying to prove his opinion to other team members, and after selecting one model, the micro group participants work together to successfully present the project to the audience.

Thus, the use of tablets helps students to present and share their thoughts, participate in discussions, create illustrative material to express their ideas as clearly as possible. This type of work contributed not only to mastering independent educational activities in computer technology, but also to organize productive communication between team members, creative development and the development of communicative and professional competences.

\section{The integration of graphics tablet technology into foreign language learning process}

Thanks to innovativeness and technical features, graphic tablets have long established themselves both among inexperienced users and among professionals in computer graphics and digital photography. But, in addition to the usual tasks that perform this kind of device on the desktop (for example, to replace the mouse at work), the functions of tablets today are actively used for other purposes that are unusual in the traditional sense. Thus, educational process can be significantly enriched by the presence of graphic input devices such as graphics tablets in the classroom.

A graphics tablet is a computer input device that enables a user to hand-draw images and graphics, similar to the way a person draws images with a pencil and paper [19]. The graphics tablet consists of a flat surface and a stylus or a pen, which can be used to produce free hand drawings or trace around shapes. The graphics tablet technology works due to the principle of absolute positioning: each point on the workspace corresponds to a certain point on the screen. Therefore, in order to move the cursor, it is enough to bring the pen or stylus to the corresponding area of the tablet. At the same time, it is not necessary to touch the surface of the working area: the tablet determines the location of the pen located at a distance of $1.5-2 \mathrm{~cm}$ from its surface. Thus, controlling the cursor with a pen requires a small number of movements and provides very high accuracy of actions.

Graphics tablets give teachers the opportunity to adjust their teaching to the unique needs of each student. Thanks to the convenient display, teachers are able to perform all the necessary manipulations, download files from the Internet and access all the necessary training materials even from previous classes. Such technologies, due to the fact that writing is carried out directly by an ergonomic pen or stylus directly on the display, make it easy to integrate students' ideas and comments into educational materials, using spontaneous notes, drafts and comments on the screen.

During the lecture, the author has practically no need to stand at the blackboard - a wireless graphic tablet allows the teacher to be anywhere in the classroom (though no more than 10 meters from a computer with a Bluetooth receiver). This allows teacher to monitor how students outline the learning material, even in the last rows of the classroom [20].

The implementation of graphics tablet technology into the process of studying foreign languages makes it easy to visualize learning material, stimulates student engagement and collaboration, supports distance and blended learning programs.

For example, while studying the topic "Tractor parts", students can work in micro groups or individually in order to describe the main principles of work and the structure of tractor main parts, visualizing them with the help of graphics tablets (Fig. 5.). Thus, they should accurately complete an illustration or scheme of particular tractor part and give a brief description of its 
peculiarities and principles of operating. All of the data is saved on their laptops and sent directly to the teacher's computer or interactive board. In such a way student revise already known material, make the necessary notes and do sketches on their own in order to prepare a detailed description. After the work on the task is completed students should present gained results to other students and participate in the discussion, which positively contributed to the development of their foreign language communicative competence.

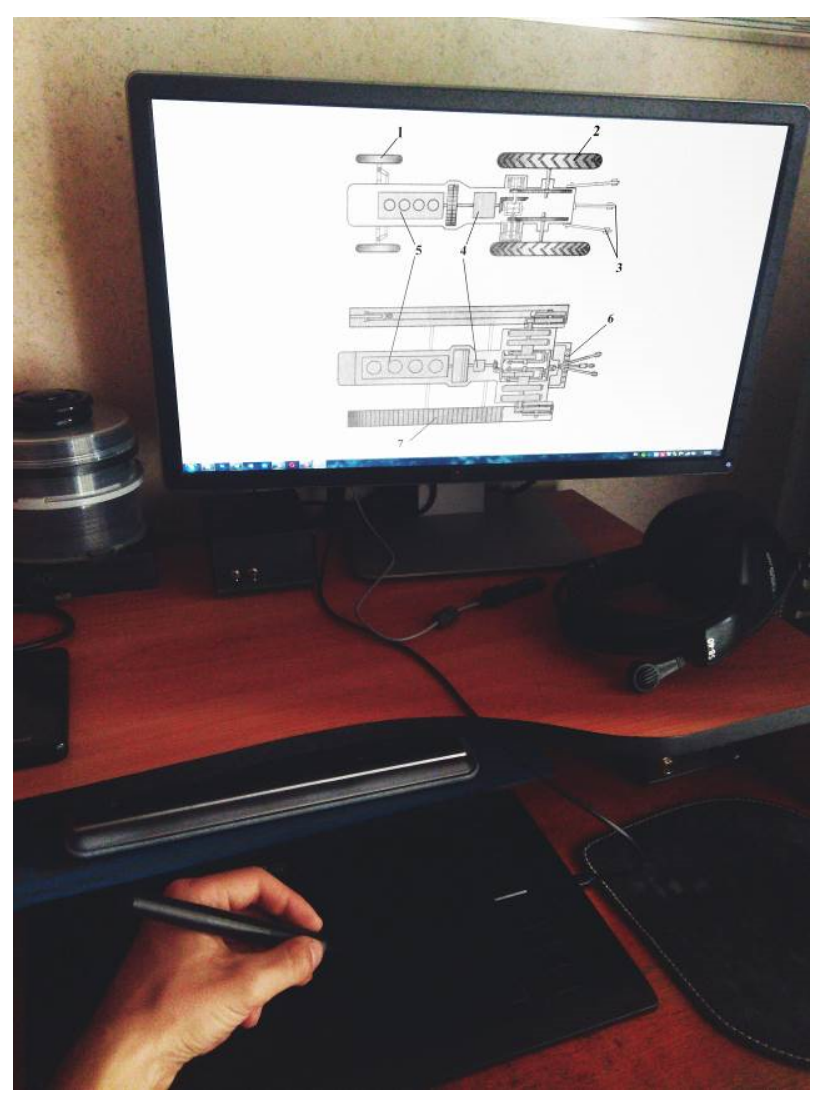

Fig. 5. Tractor sketches made by students.

One of the most important advantages of the graphics tablets is their application independence. It is not just tied to being used within a specific graphics application like Adobe Photoshop or Corel Draw. Students can choose the most convenient and appropriate software by themselves. On the other hand, both teachers and students need special training on working with graphics tablets and spend a great amount of time on practice.

\section{The influence of ICT on the process of learning English for specific purposes: results of conducted research}

For the purpose of the research the data received, after several surveys among TSATU students had been carried out, was analysed. The research has been conducted in two groups - experimental and control, including 45 and 44 students respectively. Before the experiment both groups had been taught by the same methods and assessed with the same materials. The experiment had proceeded through several stages. At the diagnostic stage of the experiment, the entry test (reading, writing, speaking and listening) had been done by the students:

- to test the level of reading skills, the participants had been asked to read the professional texts without vocabulary and complete the reading comprehension task;

- to test the level of writing skills, a lexical and grammar test and writing a letter to foreign partners or the general manager of the company, etc., had been performed;

- to test the level of speaking skills, monologue and dialogue speech had been evaluated within professional topics. During the testing, not only the content of communicative interaction had been taken into account, but also lexical and grammatical features of speech, application of socio-cultural knowledge;

- to test the ability of comprehension the job-related texts, listening the authentic audio materials had been carried out.

All students had been evaluated according to the European Credit Transfer and Accumulation System (ECTS) grading scale. Those ones who had Grade A are represented in group "Excellent", Grade B - "Very good", Grade C - "Good", Grades D and E "Satisfactory". The results of the experiment are shown in the Fig. 6.

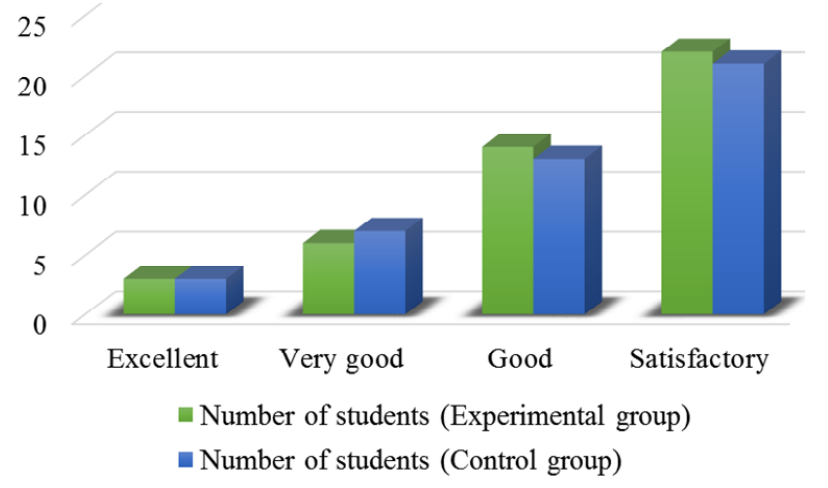

Fig. 6. The results of the entry test at the diagnostic stage of the experiment.

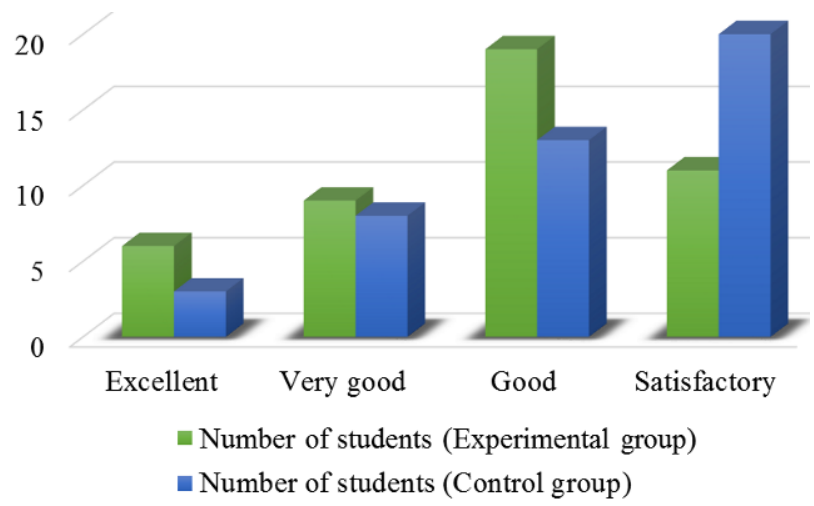

Fig. 7. The results of the control test after completing the experimental training.

On the next stage ICT had been implemented into the process of learning the course of English for specific purposes. The ESP class in the control group included 
the same topics as in the experimental group, but teaching methods and materials remained traditional and unchanged.

The control test has been performed after completing the experimental training. In order to achieve the most accurate results, the data obtained in the experimental group have been compared with the results of the control group. After processing the obtained data, it became obvious that ICT have contributed to the development of the professional communicative competence at high level and positively influenced the quality of knowledge gained while learning the course of English for specific purposes. All obtained data can be seen in the Fig. 7.

\section{Conclusions}

The conducted research makes it possible to stress the necessity of information technology implementation into the process of learning foreign language for specific purposes. The basic principles of modern methods of foreign language teaching are: movement from the whole to the individual, student orientation (learnercentered lessons), purposefulness and content of the lessons, their focus on achieving social interaction, integrating the language and mastering it with the help of knowledge from other fields of science.

The realization of these methods today is almost impossible without application of different technological means such as computers, laptops, whiteboards, tablet PCs and graphics tablets. In foreign language classes, these ICT tools provide a greater opportunity to develop students' educational, informative and communicative competences which are of high demand for sustainable future development. Thanks to information and communication technologies, teachers can solve a number of didactic tasks, namely:

- to develop skills and abilities of reading, writing, listening and speaking, using the materials of the global network;

- to replenish students' vocabulary;

- to form a strong motivation for students to learn a foreign language.

The use of these information and communication technologies provides greater flexibility of the learning process, active interaction between the teacher and students, as well as between the students themselves, openness, mobility and prompt exchange of information.

It should be mentioned that the use of computer technology in the learning process affects the growth of professional competence of teachers. It contributes to a significant increase in the quality of education, which leads to the solution of the main task of educational policy.

Analysing the experience of using ICT in ESP lessons, we can confidently say that the use of information and communication technologies allowed:

- to conduct lessons at a high aesthetic and emotional level (music, animation);

- to increase the effectiveness of the lesson;

- to provide positive motivation for learning;
- to increase the volume of work performed in the lesson in $1.5-2$ times;

- to provide a high degree of differentiation of education;

- to improve knowledge control;

- to provide access to various reference systems, electronic libraries, other information resources;

- to rationally organize the educational process.

The experimental data confirmed the effectiveness of the information and communication technologies implementation into the process of ESP learning. The results obtained during the experiment indicate that the students of the experimental group, in comparison with the students of the control group, have positively changed the level of foreign language professional competence, motivation to learn a foreign language, formed a positive attitude to self-education and selfrealization.

The prospect of further research is seen in the conducting experimental studies on the practical application of other types of ICT in the English language learning process in order to select the most effective ones.

\section{References}

1. Resolution adopted by the General Assembly on 25 September 2015. 70/1 Transforming our world: the 2030 Agenda for Sustainable Development (2015), https://www.un.org/en/development/desa/population /migration/generalassembly/docs/globalcompact/A_ RES_70_1_E.pdf. Accessed 21 Jan 2020

2. Educational content up close. Examining the learning dimensions of Education for Sustainable Development and Global Citizenship Education UNESCO. (UNESCO, 2015), https://unesdoc. unesco.org/ark:/48223/pf0000372327. Accessed 12 Feb 2020

3. G.N. Hafifah, in Proceedings of MELTC (Muhammadiyah English Language Teaching Conference), The University of Muhammadiyah Surabaya, Surabaya, 21 April 2019

4. S.V. Symonenko, N.V. Zaitseva, V.V. Osadchyi, K.P. Osadcha, E.O. Shmeltser, CEUR Workshop Proceedings 2547, 37-49 (2020)

5. H. Bakayeva et al., English for Specific Purposes (ESP). National Curriculum for Universities, (Lenvit, Kyiv, 2005), p. 119

6. V. Klochko, Formation of professionally directed foreign language competence of specialists of technical and economic specialties by means of modern information technologies (VNTU, Vinnytsia, 2009), p. 196

7. O. Shmyrova, M. Nosenko, Yo. Scien. 12.1(52.1), 84-86 (2017)

8. M.R. Ahmadi, The Use of Technology in English Language Learning: A Literature Review. IJREE 3(2), 115-125 (2018). doi:10.29252/ijree.3.2.115

9. S. Lazarenko, A. Shamsitdinov, Sc. not. of the Nat. Un. Ostr. Acad. 52, 157-159 (2015) 
10. S. Symonenko, V. Osadchyi, Peculiarities of English Language Training for Electrical Engineering Students at Ukrainian Universities. MEES. 394-397 (2019). doi:10.1109/MEES.2019.8896541

11. B. Drayton, J.K. Falk, R. Stroud, K. Hobbs, J. Hammerman, JTLA 9(3), 1-57 (2010)

12. I. I. AbdulMahmoud, Information Communication Technologies in ELT. JLTR 13 211-214 (2010). doi:10.4304/jltr.1.3.211-214

13. N. Stanić, J. Gavrilović, in Zbornik radova sa Međunarodne konferencije Sinergija (Univerzitet Sinergija, Bijeljina, 2011)

14. Regulations on the educational and methodological complex of the discipline at the Tavria State Agrotechnological University (2017), http://www.tsatu.edu.ua/nmc/osvitnyjproces/polozhennja/. Accessed 10 Feb 2020

15. M.D. Milovanović, M.A. Radić, M.S. Branisavljević, J.D. Petrović, Inovatcije u nastavi. XXVIII, 130-139 (2015)

16. R. Kaziev, The use of interactive teaching aids in education (Tarko-Sale, 2015), p. 22

17. O. Akbaş, H.M. Pektaş, APFSLT 12.2, 1-19 (2011)

18. C. Hong, A Tablet Based Learning environment (JOUR, 2014), https://www.researchgate.net/ publication/261066108_A_Tablet_Based_Learning Environment. Accessed 15 Jan 2020

19. M. Evans, N. Aldoy, The Des. Jour. - An Int. Jour. for All Asp. of Des. 5, 763-787 (2016)

20. A. Carrillo, J.M. Cejudo, F. Domínguez, \& E. Rodríguez, Graphics tablet technology in second year thermal engineering teaching. JOTSE 3(3), 102-112 (2013). doi:10.3926/jotse. 85. 